\title{
Effect of Message Framing on Improving Physical Activity in Women with Type 2 Diabetes
}

\author{
Z Baji ${ }^{1,}$; F Zamani Alavijeh ${ }^{2}$; Gh Shakerinejad ${ }^{3}$; M Tehrani ${ }^{4}$ \\ ${ }^{1}$ MSc of Health Education, Health Education Research Department, ACECR-Khuzestan, Ahvaz, Iran \\ ${ }^{2}$ Assistant Professor of Health Education, Department of Public Health, Social Determinants of Health Research Centre, School of Health, Ahvaz Jundishapur Medical Sciences \\ University, Ahvaz, Iran \\ ${ }^{3}$ Associate Professor of Health Education, Health Education Research Department, ACECR-Khuzestan, Ahvaz, Iran \\ ${ }^{4}$ MSc of Nutrition, Health Education Research Department, ACECR-Khuzestan, Ahvaz, Iran \\ ${ }^{*}$ Corresponding author: Z Baji, MSc of Health Education, Health Education Research Group, ACECR-Khuzestan, Ahvaz, P.O. Box: 6135733773, Iran. Tel: +98-6133330023, E-mail: zahra- \\ baji65@yahoo.com
}

Received: 11 Dec 2016

Accepted: 01 Jan 2017

Epub: 23 Feb 2017

Ppub: 15 Jan 2018

\begin{abstract}
Background: The effectiveness of the educational message for motivating to change behavior may be greater than the actual content of a message, depending on how the message is designed.

objective: The purpose of this study was to compare the effectiveness of gain and loss framed messages on increased physical activity in women with type 2 diabetes attending a diabetes clinic in Ahvaz city.

Methods: This randomized clinical trial study was performed among 119 patients with type 2 diabetes who were referred to the diabetes clinic in Ahvaz in 2014. Patients were selected by convenience sampling and then randomly divided into gain (59 cases) and loss (60 cases) groups by use of random numbers table. Two groups received physical activity educational messages in a different context via short message service for 2 months. The data in this study were collected by using a standard 3-part questionnaire as well as interviews before and 1 month after intervention. Data were analyzed by using SPSS version 16 by descriptive statistics, independent t-test, and Chi-square.

Results: Based on the finding before the intervention, 2 groups were similar of individual variables, the mean score of physical activity, and disease characteristics. After the intervention, the mean score of physical activity in both groups showed a significant increase $(\mathrm{P}<0.05)$. The results showed that patients who were faced with the loss framed messages compared to patients who were confronted to gain framed messages have more motivation for physical activity $(\mathrm{P}<0.05)$.

Conclusion: The present study indicates that loss framed messages are effective in increasing physical activity behaviors in women with type 2 diabetes.
\end{abstract}

Keywords: Type 2 Diabetes; Physical Activity; Women with Type 2 Diabetes; Message Framing 